\title{
Stromal vascular fraction cells of adipose and connective tissue in people with osteoarthritis: A case control prospective multi-centric non-randomized study
}

Jaroslav Michalek ${ }^{1,11 *}$, Rene Moster ${ }^{2}$, Ladislav Lukac ${ }^{3}$, Kenneth Proefrock ${ }^{4}$, Miron Petrasovic ${ }^{5}$, Jakub Rybar ${ }^{5}$, Ales Chaloupka ${ }^{6}$, Adas Darinskas $^{7}$, Jaroslav Michalek ${ }^{8}$, Jan Kristek ${ }^{9}$, Jan Travnik ${ }^{10}$, Petr Jabandziev ${ }^{11}$, Marek Cibulka ${ }^{1}$, Josef Skopalik ${ }^{1}$, Zlatuse Kristkova ${ }^{1}$ and Zuzana Dudasova $^{1}$

${ }^{1}$ International Consortium for Cell Therapy and Immunotherapy, registered consortium, Brno, Czech Republic

${ }^{2}$ Revmacenter, Brno, Czech Republic

${ }^{3}$ ArthroBiotherapy, Ostrava, Czech Republic

${ }^{4}$ Stem Cell Center, Phoenix, AZ, USA

${ }^{5}$ Medissimo Hospital, Bratislava, Slovakia

${ }^{6}$ First Surgery, Pardubice, Czech Republic

${ }^{7}$ Department of Pharmacology, Lithuanian University of Health Sciences, Kaunas, Lithuania

${ }^{8}$ Department of Econometrics, University of Defense, Brno, Czech Republic

${ }^{9}$ Department of Radiology, Surgal Clinic, Brno, Czech Republic

${ }^{10}$ Department of Orthopedics, Traumatology Hospital, Brno, Czech Republic

${ }^{11}$ Department of Pediatrics, University Hospital Brno, Brno, Czech Republic

\begin{abstract}
Objective: Stromal vascular fraction (SVF), containing high amount of stem cells and other regenerative cells, can be easily obtained from loose connective tissue that is associated with adipose tissue. Here we evaluated safety and clinical efficacy of freshly isolated autologous SVF cells in a case control prospective multi-centric non-randomized study in patients with grade 2-4 degenerative osteoarthritis.

Methods: A total of 1128 patients underwent standard liposuction under local anesthesia and SVF cells were isolated and prepared for application into 1-4 large joints. A total of 1856 joints, mainly knee and hip joints, were treated with a single dose of SVF cells. 1114 patients were followed for $12.1-54.3$ months (median 17.2 months) for safety and efficacy. Modified KOOS/HOOS Clinical Score was used to evaluate clinical effect and was based on pain, non-steroid analgesic usage, limping, extent of joint movement, and joint stiffness evaluation before and at 3,6 and 12 months after the treatment.

Results: No serious side effects, systemic infection or cancer was associated with SVF cell therapy. Most patients gradually improved 3-12 months after the treatment. At least $75 \%$ Score improvement was noticed in $63 \%$ of patients and at least $50 \%$ Score improvement was documented in $91 \%$ of patients 12 months after SVF cell therapy. Obesity and higher grade of OA were associated with slower healing.

Conclusion: Here we report a novel and promising treatment approach for patients with degenerative osteoarthritis that is safe, cost-effective, and relying only on autologous cells.
\end{abstract}

\section{Introduction}

Degenerative osteoarthritis (OA) of large joints, especially hip and knee, is characterized by degeneration of articular cartilage, sclerosis of the subchondral bone, and marginal osteophyte formation. In the United States of America, symptomatic OA is present in $13.9 \%$ of adults 25 years and older and in $33.6 \%$ of adults 65 years and older, but it is estimated that radiographic OA is much more frequent [1]. OA of weight-bearing joints is associated with chronic devastating pain, stiffness, decreasing range of motion and joint deformity, being one of the leading causes of decreased quality of life and work limitations in elderly.

Although early stages of OA can be alleviated by physical therapy, weight loss, non-steroid analgesic drugs, and chondroprotectives, the advanced disease relies on total joint replacement. Total joint arthroplasty (TJA) is the mainstay of treatment for end-stage OA of the hip or knee. Unfortunately, TJA is relatively frequently associated with serious and life-threatening complications including increased risk of infection, thromboembolism, myocardial infarction, stroke, increased

Correspondence to: Jaroslav Michalek, International Consortium for Cell Therapy and Immunotherapy, Videnska 119, Brno 61900, Czech Republic, Tel: +420-511-181-555; E-mail: michalek@iccti.eu

Key words: stromal vascular fraction, cells, adipose tissue, connective tissue, osteoarthritis, stem cell therapy, treatment

Received: April 28, 2017; Accepted: May 26, 2017; Published: May 29, 2017 
Michalek J (2017) Stromal vascular fraction cells of adipose and connective tissue in patients with osteoarthritis: A case control prospective multi-centric nonrandomized study

risk of death at 30 and 90 days after surgery, and the life-span of the prosthesis is limited [2-5].

Recently, it was shown that mesenchymal stromal/stem cells (MSCs) hold a great promise for their healing potential in regenerative medicine [6]. Preclinical animal studies that utilize MSCs demonstrated safety and efficacy in treatment of OA, cartilage defects or other orthopedic conditions [7-10]. In humans, the largest collection of culture-expanded bone marrow-derived MSCs used for treatment of 339 patients with OA was recently documented and more than $75 \%$ improvement was reported in $41.4 \%$ and more than $50 \%$ improvement was reported in $63.2 \%$ of patients [11]. No severe side effects and no neoplastic complications were detected at any stem cell re-implantation site in a mean follow-up 435 days [11].

MSCs can be obtained from bone marrow as well as from adipose tissue. Although bone marrow MSCs and adipose tissue-derived MSCs share many biological features, there are also some differences. Adipose tissue-derived MSCs are more genetically stable in a long term culture, display a lower senescence ratio and higher proliferative capacity [10]. Bone marrow MSCs constitute only about $0.001 \%-0.01 \%$ of all nucleated cells in bone marrow, whereas the amount of adipose tissue-derived MSCs is approximately 1000-fold greater when isolated from equivalent volume of tissue $[10,12,13]$. Adipose tissue can be easily obtained by standard liposuction under local anesthesia and isolated stromal vascular fraction (SVF) cells contain 1-4\% MSCs as well as other cell types involved in tissue regeneration such as vascular endothelial cells, pericytes, fibroblasts, macrophages and regulatory $\mathrm{T}$ lymphocytes [10,14-16]. SVF cells demonstrated anti-inflammatory and immunomodulatory effects and MSCs have the capacity to differentiate into connective tissue cells including cartilage, tendon and ligament $[10,17]$. SVF cells can be clinically used as freshly isolated from the lipoaspirate without further in vitro expansion or manipulation. These various SVF cell components may act synergistically with MSCs and therefore may be superior to MSCs alone [13]. It may be also presumed that freshly isolated cells would be safer and more efficacious compared with the cells expanded by culture, as ex vivo manipulations may lead to genetic and epigenetic alterations that may affect the functional and biological properties of the cells [18].

Autologous adipose-derived SVF cell therapy has been used since 2003 in dogs. In a randomized double-blinded multicenter controlled trial, dogs with large joint OA treated with SVF cells had significantly improved scores for pain, lameness and range of motion compared with control dogs [7]. At least 80,000 SVF cells per kilogram of animal body weight were used. Similar effects were documented for OA, cartilage, tendon and ligament injuries treated with autologous SVF cells in other species as well $[7,19,20]$.

Based on previously published results from animal and human studies, we hypothesize that non-manipulated SVF cells freshly isolated from loose connective tissue that is associated with adipose tissue and administered to the loose connective tissue in a close proximity or into the arthritic joint can demonstrate healing potential in patients with degenerative OA. Here we present data from a multi-centric, prospective case control study that demonstrate how practicing medicine with patient's own regenerative cells freshly isolated from a stromal vascular fraction surrounding small blood vessels of the adipose tissue can significantly improve outcome of degenerative OA leading to a better quality of life.

\section{Materials and methods}

\section{Patients}

Multi-centric prospective non-randomized case control study of International Consortium for Cell Therapy and Immunotherapy (ICCTI) was performed in the United States of America, the Czech Republic, Slovakia, and Lithuania after approval by the local Ethics Committees and Investigational Review Board of American Naturopathic Research Institute/Naturopathic Oncology Research Institute. Informed consent for patients was in accordance with the Declaration of Helsinki. Certified orthopedic surgeons and/or traumatology surgeons recruited patients with $\mathrm{OA}$ in seven clinical centers from 2010 to 2013. Inclusion criteria consisted of: 1) 18 years of age and older; 2) chronic or degenerative joint OA grade 2-4 (KellgrenLawrence) of 1-4 large weight bearing joints (including hip and knee) and additionally 0-8 other joints (including shoulder, elbow, wrist, hand, ankle, foot) causing significant functional disability verified by clinical examination and X-ray and/or magnetic resonance imaging (MRI); 3) failure of conservative management; 4) signed informed consent form. Exclusion criteria consisted of: 1) active inflammatory disease; 2) severe cardiac, pulmonary or other systemic disease; 3) history of active neoplasm and its treatment with immunosuppressive agents (including chemotherapy, radiotherapy, steroids or other immunosuppressive drugs) within the past 12 months; 4) steroids or platelet-rich plasma within the past 4 weeks; 5) health condition (including known allergy to local anesthetic drug) that does not allow to perform liposuction in local anesthesia; 6) pregnancy or lactation; 7) TJA.

Patients who were referred as candidates for TJA were allowed to participate in SVF cell therapy and this information was recorded by referring physician. All patients underwent local anesthesia of subcutaneous fat in an extent that enables collection of $20-200 \mathrm{ml}$ of adipose tissue (lipoaspirate) by a standard tumescent liposuction.

\section{$\mathrm{X}$-ray and magnetic resonance imaging}

$\mathrm{X}$-ray: standard weight-bearing X-ray images were performed in antero-posterior (AP) and lateral projections. The images were taken at collaborating institutions using digital X-ray machines, all of them were quality-controlled and certified. Most images were made on direct radiography system Sedecal CXDI 55G (Spain) with read-out detector Canon CXDI (Japan).

MRI: $1.5 \mathrm{~T}$ standard protocols pertaining each individual joint using proton density-weighted images $(\mathrm{PD})$ and $\mathrm{PD}$ with fat saturation (FS) in coronal plane, T1 and PD FS in sagittal plane, 3D waterexcitation technique in transversal and coronal planes were applied. Examinations were performed on $1.5 \mathrm{~T}$ machine Toshiba Excelart Vantage (Toshiba Medical Systems, Japan).

\section{Tissue and SVF Cell Processing}

Lipoaspirate was processed using Cellthera Kit I (patented technology: EP No. 2792741 in 2010-2012) or Cellthera Kit II (in 2013), Cellthera, s.r.o., Brno, Czech Republic. At least $20 \mathrm{ml}$ of adipose tissue per each large joint (or 2 medium joints - elbow, wrist; or 5-8 small joints - hand, foot) treated was processed according to manufacturer's instructions with Cellthera Kit I containing collagenase mix. Finally, to block any residual collagenase activity, SVF cells isolated by Kit I were resuspended in $1-5 \mathrm{ml}$ autologous plasma that was obtained from anticoagulated blood after centrifugation. When using Kit II, at least $50 \mathrm{ml}$ of adipose tissue per each large joint (or 2 medium joints - elbow, 
Michalek J (2017) Stromal vascular fraction cells of adipose and connective tissue in patients with osteoarthritis: A case control prospective multi-centric nonrandomized study

wrist; or 5-8 small joints - hand, foot) treated was processed with Cellthera Kit II that does not contain collagenase. Briefly, lipoaspirate was thoroughly washed to remove most red blood cells and tissue debris, incubated at $37^{\circ} \mathrm{C}$ for $20-30$ minutes while shaking and SVF cells were then collected by centrifugation at $400 \mathrm{~g}$, properly washed with normal saline and filtered through a sterile $100 \mu \mathrm{m}$ filter (BD Biosciences, Franklin Lakes, NJ, USA). SVF cells isolated by Kit II were resuspended in $1-5 \mathrm{ml}$ normal saline. All isolated SVF cells were used for treatment. In both cases (isolation using Kit I or Kit II), all nucleated SVF cells were counted on Burker chamber (Glaswarenfabrik Karl Hecht GmbH \& Co KG, Sondheim/Rhön, Germany) after trypan blue (Sigma-Aldrich, St Louis, MO, USA) staining.

\section{In vitro SVF cells preclinical testing}

Freshly isolated SVF cells as well as third passage adipose tissue-derived stromal cells (ASCs) were examined for their immunophenotype. In order to obtain the third passage of ASC, isolated SVF cells were seeded at a density $20 \times 10^{3} \mathrm{cells} / \mathrm{cm}^{2}$ in 24-well plastic plate (Costar, USA), and then cultured in DMEM/F12 (SigmaAldrich) containing $2 \%$ penicillin and $5 \%$ platelet lysate at $37^{\circ} \mathrm{C}$ with $5 \% \mathrm{CO}_{2}$. After 24 hours of culture, non-adherent cells were removed and fresh complete medium was added to adherent cells - ASCs. The medium was changed twice per week. When $80 \%$ confluence was reached, the cells were counted and subcultured using $0.25 \%$ trypsin (Sigma-Aldrich).

The immunophenotype of SVF freshly isolated cells as well as third passage ASCs was characterized by BD FACS Canto II flow cytometer (BD Biosciences). Briefly, cells were washed twice in Dulbeco's PBS containing $1 \%$ bovine serum albumin (Sigma-Aldrich) and stained for 30 minutes at $4^{\circ} \mathrm{C}$ with anti-CD90 - FITC, anti-CD73 - PE, anti-CD105 - APC, anti-CD19 - APC-Cy7, anti-CD45- PECy7 and anti-CD34 PerCP-Cy5 (BD Biosciences). Cells were then washed with PBS and characterized by flow cytometry. Doubling time (DT) was measured as followed: DT $=(\log 2 \times$ culture time $):\left(\log \mathrm{N}-\log \mathrm{N}_{0}\right)$ where $\mathrm{N}$ is cell count after the third passage and $\mathrm{N}_{0}$ is cell count of adherent cells after removal of non-adherent cells at the beginning of cell culture.

\section{Treatments}

SVF cells were administered in $1-5 \mathrm{ml}$ aliquot per joint treated according to joint size. Up to 4 large joints or up to 8 other joints were treated. Single injection of SVF cells was administered intraarticularly or periarticularly to the synovial stromal loose connective tissue in the close proximity of such joint. If needed, ultrasound or C-arm X-ray navigation of the needle was employed.

\section{Evaluations}

Clinical status of all patients was closely monitored by the attending physician who indicated patients for cell therapy at least 1 week before, at the time of SVF treatment, 1 week, 1, 3, 6, and 12 months after the SVF treatment. SVF cell therapy was recorded and evaluated by the same physician. Clinical evaluation incorporated medical history, physical examination including evaluation of joint pain, number of analgesic drugs taken, joint stiffness and extent of joint movement, lameness status on a semiquantitative scale, recommendation for TJA, as well as any side effects possibly associated with SVF cell therapy. If possible, joint X-ray and/or MRI follow-up of the involved joint was performed after at least 6 months from SVF cell therapy.

All patients and their physicians were instructed to fill in the modified Knee/Hip Osteoarthritis Outcome Score (KOOS/HOOS; www.koos.nu) questionnaire that evaluated semiquantitatively the following measures:

A) Pain - patient evaluation $(0=$ no pain; $1=$ minor not frequent pain; $2=$ minor frequent pain; $3=$ moderate pain; $4=$ severe pain; $5=$ unbearable pain requiring analgesics);

B) Painkillers per week - physician evaluation ( $0=$ no painkillers; 1 $=1-7$ pills/topical analgesic cream $(\mathrm{TAC}) ; 2=8-14$ pills/TAC; $3=15-21$ pills/TAC; $4=22-28$ pills/TAC; $5=29$ or more pills/TAC);

C) Limping at walk - physician evaluation $(0=$ no limping; $1=$ less frequent minor limping; $2=$ frequent minor limping; $3=$ moderate limping; 4 = severe limping; 5 = impossible to walk);

D) Extent of joint movement- physician evaluation $(0=$ no limitation; $1=$ limitation up to $20 \% ; 2=$ limitation $21-40 \% ; 3=$ limitation $41-60 \% ; 4=$ limitation $61-80 \% ; 5=$ limitation more than $80 \%$, impossible to move);

E) Joint stiffness - patient evaluation $(0=$ no stiffness; $1=$ minor; 2 = moderate; 3 = serious; $4=$ severe; $5=$ impossible to walk).

OA Score was then constructed as the mean value of variables A) - E) for each patient.

\section{Statistical evaluation}

The nonparametric statistical analysis of changes in Scores over time (before, 3months, 6months and 12 months) in each treatment group was tested by one-way repeated measures analysis of variance (ANOVA), the Friedman test was used. The Kruskal-Wallis test (nonparametric one-way ANOVA) was used for comparing Score in independent treatment group (according to OA grade, and body mass index (BMI) category) and post hoc comparisons were made. Wilcoxon rank test was used for comparisons of independent pairs of groups and the Bonferroni correction was used for the test modification to multiple comparisons. Correlation analysis (Spearman correlation coefficient and also modified Spearman correlation coefficient for categorized data) was used for description of statistical association between studied variables (Score and BMI, Score and OA grade, etc.). The significance level 0.05 was used throughout. The $50 \%$ and $75 \%$ effect of Score improvement in time was calculated as a percentage of patients where the difference between Score before and Score in a particular time was greater than half and $3 / 4$ of Score before, respectively. The data were analyzed using statistical software STATISTICA v.10 StatSoft, Inc.

\section{Results}

\section{Patient characteristics}

A total of 1856 joints of 1128 unique patients were treated with single injection of SVF cells isolated from autologous adipose tissue. From this large group 14 patients (1.2\%) were lost to follow-up and $1114(98.8 \%)$ patients were evaluated at their follow-up visits. Median follow-up time from the procedure was 17.2 months (range 12.154.3 months). The median age was 62 years (range 19-94 years), 596 (52.8\%) patients were males and $532(47.2 \%)$ were females, all patients were Caucasians and all underwent single procedure of SVF cell administration to 1-8 joints. There were 557 (49.4\%) patients with one joint treated, $481(42.6 \%)$ patients with two joints treated, $51(4.5 \%)$ patients with three joints treated, and 39 (3.5\%) patients with four to eight joints treated. Patients underwent 1132 (61.0\%) knee procedures, 625 (33.7\%) hip procedures, and 99 (5.3\%) other joint (ankle, foot, shoulder, hand, wrist or elbow) procedures (Figure 1). Based on 
Michalek J (2017) Stromal vascular fraction cells of adipose and connective tissue in patients with osteoarthritis: A case control prospective multi-centric nonrandomized study
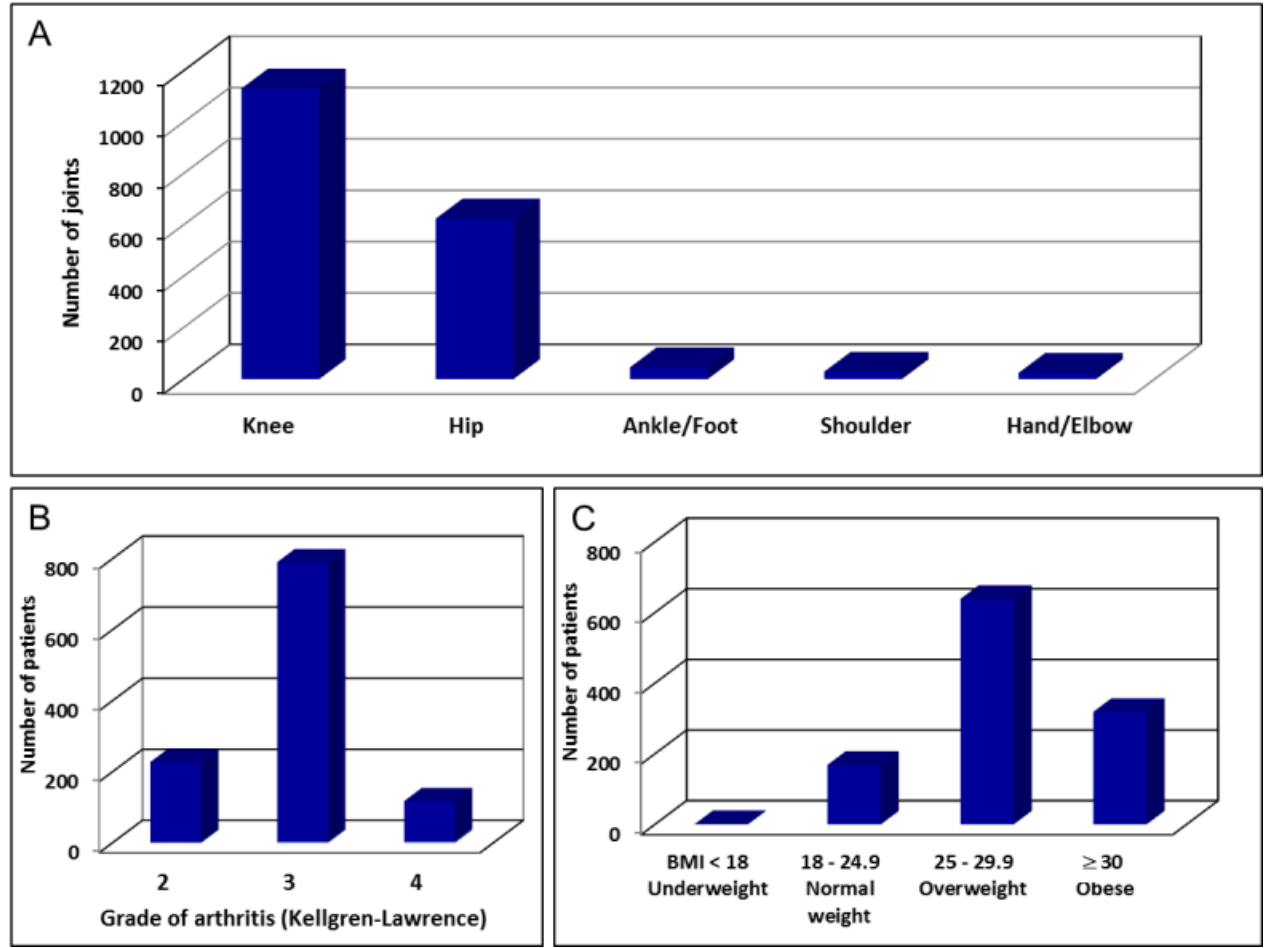

Figure 1. Characteristics of patients and joints treated by SVF cell therapy.

(A): 1856 joints in 1128 patients were treated. The columns represent the numbers of knee, hip, ankle/foot, shoulder and hand/elbow joints treated. (B): The number of patients diagnosed with grade 2, 3 and 4 (according to Kellgren-Lawrence classification) of osteoarthritis is shown. (C): The body mass index (BMI) of patients undergoing SVF cell therapy.

clinical and X-ray examination, $226(20.0 \%)$ patients were diagnosed with grade 2, $788(69.9 \%)$ with grade 3 , and $114(10.1 \%)$ with grade 4 of degenerative OA (highest grade of OA in each patient is reported). There was 1 (0.1\%) underweight patient (BMI bellow 18), $169(15.0 \%)$ patients with normal weight (BMI 18-24.9), 639 (56.6\%) overweight patients (BMI 25-29.9), and 319 (28.3\%) obese patients (BMI 30 or over) (Figure 1). Among all patients treated, there was always at least one large joint (hip or knee) treated and 503 patients (45.2\%) of 1114 patients followed-up were candidates for TJA.

\section{SVF cell characteristics}

Initially, we compared isolation of SVF cells from autologous adipose tissue using Cellthera Kit I and Kit II. In the cohort of 12 patient samples of isolated SVF cells (6 isolated with Kit I and 6 isolated with Kit II) we were able to demonstrate typical ASC characteristics including $0.9-4.7 \%$ of plastic adherent cells and growing in vitro up to passage 6 and expressing CD73, CD90, CD105, losing expression of CD34 and negative for CD45 (data not shown). No significant difference in doubling time was noticed between cells isolated with Kit I and Kit II. In this preliminary optimization cohort, the yield of isolated viable SVF cells per $\mathrm{ml}$ of adipose tissue was 3.4-fold higher when using Kit I compared to Kit II.

Thus, for the clinical protocol of individualized cell therapy with autologous SVF cells we decided to use $20-30 \mathrm{ml}$ of adipose tissue per each large joint treated when Kit I was used, and 50-90ml of adipose tissue per each large joint treated when Kit II was used. Kit I was used in 478 patients and led to nucleated SVF mean cell yield of $1.63( \pm 0.41)$ $\mathrm{x} 10^{6} / \mathrm{ml}$ of adipose tissue and viability of $87.4 \%$ ( $\left.\pm 6.7 \%\right)$. Kit II was used in 650 patients and led to nucleated SVF mean cell yield of 0.39 $( \pm 0.12) \times 10^{6} / \mathrm{ml}$ of adipose tissue and viability of $95.8 \%( \pm 3.9 \%)$. Absolute number of viable SVF cells obtained from adipose tissue isolated with Kit I reached $28.4( \pm 11.7) \times 10^{6}$ while absolute number of viable SVF cells obtained from adipose tissue isolated with Kit II reached $22.5( \pm 8.1) \times 10^{6}$. These absolute numbers of viable SVF cells were not significantly different $(\mathrm{p}=0.19)$. No statistically significant differences in age, sex, BMI and degree of OA were noticed between patients treated with cells isolated with Kit I or Kit II.

\section{SVF cell therapy and patient follow-up}

All patients underwent treatment with SVF cells as scheduled and no complications related to adipose tissue processing and SVF cells preparation were noticed. There were no serious side effects associated with SVF cell therapy. Other side effects related to the procedure consisted of local pain and swelling at the site of injection, fever, reactive synovitis, headache, deep venous thrombosis (Table 1). Pain and swelling at the site of injection were observed in patients injected with higher cell number but without significant difference between those treated with Kit I or Kit II isolated cells. Both cases of deep venous thrombosis occurred in women with unsatisfactory hydration and refusal to walk while remaining at sitting position for several hours after the procedure. There was one case of infectious synovitis reported that is unlikely to be SVF cell therapy-related but it is not possible to exclude it. Six days after SVF cell therapy a woman was complaining of localized pain and swelling at the site of SVF cell application and was admitted to another hospital where a puncture of right knee was performed and revealed to be sterile. Four days later, synovectomy of the right knee was performed and S. epidermidis was cultured.

Approximately $95 \%$ of joints treated were knees and/or hips (Figure 1). Clinical effect of SVF cell therapy was evaluated with modified KOOS/HOOS Score since, based on Inclusion criteria, all patients has to be treated for at least one hip or knee joint. SVF cell application revealed at least $50 \%$ improvement of hip or knee joint after treatment 
Michalek J (2017) Stromal vascular fraction cells of adipose and connective tissue in patients with osteoarthritis: A case control prospective multi-centric nonrandomized study

Table 1. Side effects observed in patients treated with SVF cell therapy.A total number of 1114 patients were treated and followed-up for side effects related to SVF cell therapy.

\begin{tabular}{|c|c|c|}
\hline Serious side effects & Number & {$[\%]$} \\
\hline Myocardial infarction & 0 & 0 \\
\hline Stroke & 0 & 0 \\
\hline Thromboembolism & 0 & 0 \\
\hline Systemic infection & 0 & 0 \\
\hline Cancer & 0 & 0 \\
\hline Death & 0 & 0 \\
\hline Other serious side effects & 0 & {$[\%]$} \\
\hline Other side effects & Number & 4.22 \\
\hline Local pain $<24$ hours & 38 & 3.41 \\
\hline Local pain $>24$ hours & 58 & 5.21 \\
\hline Local swelling $<72$ hours & 12 & 1.08 \\
\hline Local swelling $>72$ hours & 9 & 0.81 \\
\hline Fever $>38^{\circ} \mathrm{C}<24$ hours & 4 & 0.36 \\
\hline Fever $>38^{\circ} \mathrm{C}>24$ hours & 5 & 0.45 \\
\hline Reactive synovitis & 3 & 0.27 \\
\hline Headache & 2 & 0.18 \\
\hline Deep venous thrombosis & 1 & 0.09 \\
\hline Infectious synovitis* & & \\
\hline
\end{tabular}

*One patient experienced infectious synovitis that was unlikely related to SVF therapy, but it is impossible to completely exclude it. For details, see text.

in $80.6 \%$ of patients at 3 months. The Score further improved in time to 12 months of the follow-up to $91.0 \%$ as documented in Figure 2. When $75 \%$ Score improvement was evaluated of the hip or knee joint, similar trend for improvement was noticed from 3 months to 12 months posttreatment in $39.7 \%$ to $63.0 \%$ of patients. Only up to $0.9 \%$ of patients were non-responders. Remaining patients improved for less than $50 \%$. There was a difference in clinical responses among patients treated with SVF cells isolated with Kit I and Kit II by multiple comparison analysis (Figure 2D). This difference was significant at 3 months after SVF cell therapy ( $p=0.0001)$, but not before, at 6 and 12 months after SVF cell therapy ( $\mathrm{p}=0.2430 ; \mathrm{p}=0.0512 ; \mathrm{p}=0.4593$, respectively).

Women had higher Score than men before and at 3 months after SVF cell therapy ( $p=0.0089 ; p=0.0020)$, but not at 6 and 12 months after the procedure $(\mathrm{p}=0.0771 ; \mathrm{p}=0.5799$, respectively $)$ as demonstrated in Figure 2E. Score evaluation before, at 3, 6 and 12 months after the SVF cell therapy was significantly increased in older patients in comparison to younger ones $(p<0.0001$ in all checkpoints, respectively) as shown in Figure 2F. Higher OA grade was associated with significantly increased OA Score before, at 3 and 6 months ( $\mathrm{p}=$ $0.0156 ; \mathrm{p}=0.0318 ; \mathrm{p}=0.0030$, respectively), but not at 12 months $(\mathrm{p}=$ $0.5315)$ after SVF therapy. Patients with higher BMI had significantly higher OA Score at 3 months after the procedure $(p=0.0281)$, but not before and at 6 and 12 months after SVF therapy $(\mathrm{p}=0.3002 ; \mathrm{p}=$ 0.1004; $\mathrm{p}=0.4022$, respectively).

Patient's responses were also monitored by X-ray and MRI. Typically subtle but significant widening of joint spaces was observed on X-ray 6 - 12 months after SVF cell therapy. MRI studies revealed slight chondral thickening or stable cartilage thickness 6 - 12 months after SVF cell therapy. Smoothing of surface irregularities and defects, regression of reactive subchondral bone edema, sealing of chondral fissures, healing of subchondral cortical lesions or integration of chondral flaps were frequently seen after the treatment. To illustrate the X-ray and MRI of the joint treated with SVF cells of a typical goodresponders (Figure 3 ).

From 503 TJA candidates before the SVF cell therapy, only $4(0.80$ $\%)$ patients required total hip replacement during the follow-up period.
These findings demonstrate that patients with lower degree of $\mathrm{OA}$ and non-obese patients recover from OA faster, typically within 3-6 months after SVF cell therapy. In patients with higher degree of OA and in obese patients the regeneration of arthritic joint may take longer, but at 12 months they experience the same degree of clinical improvement as patients with lower degree of $\mathrm{OA}$ and non-obese patients, respectively.

\section{Discussion}

Adipose-derived cells have potential applications to a wide range of clinical disorders including myocardial infarction, stroke, Crohn's disease, multiple sclerosis, rheumatoid arthritis, limb ischemia, breast augmentation and reconstruction, decubiti ulcers, postirradiation fibrosis, and craniofacial reconstruction $[6,21,22]$.The greatest number of patients reported have been for breast reconstruction, myocardial infarction, and fistula repair in Crohn's disease as previously reviewed $[10,15]$.

There is also a growing body of research regarding stem cells for the treatment of degenerative OA. Recently, the largest group of patients with OA treated with bone marrow-derived cultured MSCs was reported by Centeno et al. and involved 339 patients. It demonstrated safety and clinical efficacy in most patients treated. In a subgroup of 133 patients with knee OA 50\% score improvement was noticed in $63.2 \%$ cases at an average reporting time of 11.3 months from the first cell application [11]. Vangsness et al. reported results of a randomized, double-blind, controlled study in 55 patients with knee OA and partial medial meniscectomy treated with allogeneic bone marrow-derived MSCs. The study demonstrated safety and no ectopic tissue formation after cell therapy. Reduction of pain as well as meniscal volume increase was noticed in MSC-treated patients but not in placebo control group [17]. Despite using different cell sources, both studies [11,17] are in accordance with our findings regarding safety and clinical effect of cell therapies in similar orthopedic indications.

Recently, there are several reports regarding adipose-derived cell therapy of degenerative $\mathrm{OA}$, but all of them with relatively small number of patients [14,16,23-25]. In our study, we are in agreement with these studies using adipose-derived cells which are safe and clinically effective in most patients with degenerative OA. The use of adipose tissue have many advantages in comparison to bone marrow: it can be easily obtained by standard liposuction under local anesthesia; adipose stem cells are plentiful and adipose tissue contains approximately 500-2500 times higher amount of mesenchymal stem cells compared to the same volume of bone marrow $[10,12,21,26]$. While MSCs are dramatically decreasing with age in bone marrow [27], their pool in adipose tissue is quite stable during life [26,27]. In addition, the adipose tissue contains unique populations of cells that suppress the inflammatory responses, and thus further contribute to tissue healing. Loose connective tissue creates an optimal environment for adaptation of stem cells and other cells contained in SVF that supports and positively affects microenvironment being sentinels for injury, damaged cells and tissues $[10,28]$. Adipose-derived stem and stromal cells do not require in vitro cultivation and are ready for use immediately after isolation from the adipose tissue. Recently, in an animal model of guinea pigs with spontaneous OA, Sato et al. demonstrated migration, differentiation, proliferation, and persistence of MSCs into the damaged cartilage and adjacent synovial tissue. There was a strong immunostaining for type II collagen around both residual chondrocytes and transplanted MSCs in the OA cartilage demonstrating direct contribution of MSCs to hyaline cartilage healing and regeneration [9].

These data are in accordance with our clinical observation in a large cohort of adult patients with grade 2-4 degenerative OA. In our 
Michalek J (2017) Stromal vascular fraction cells of adipose and connective tissue in patients with osteoarthritis: A case control prospective multi-centric nonrandomized study
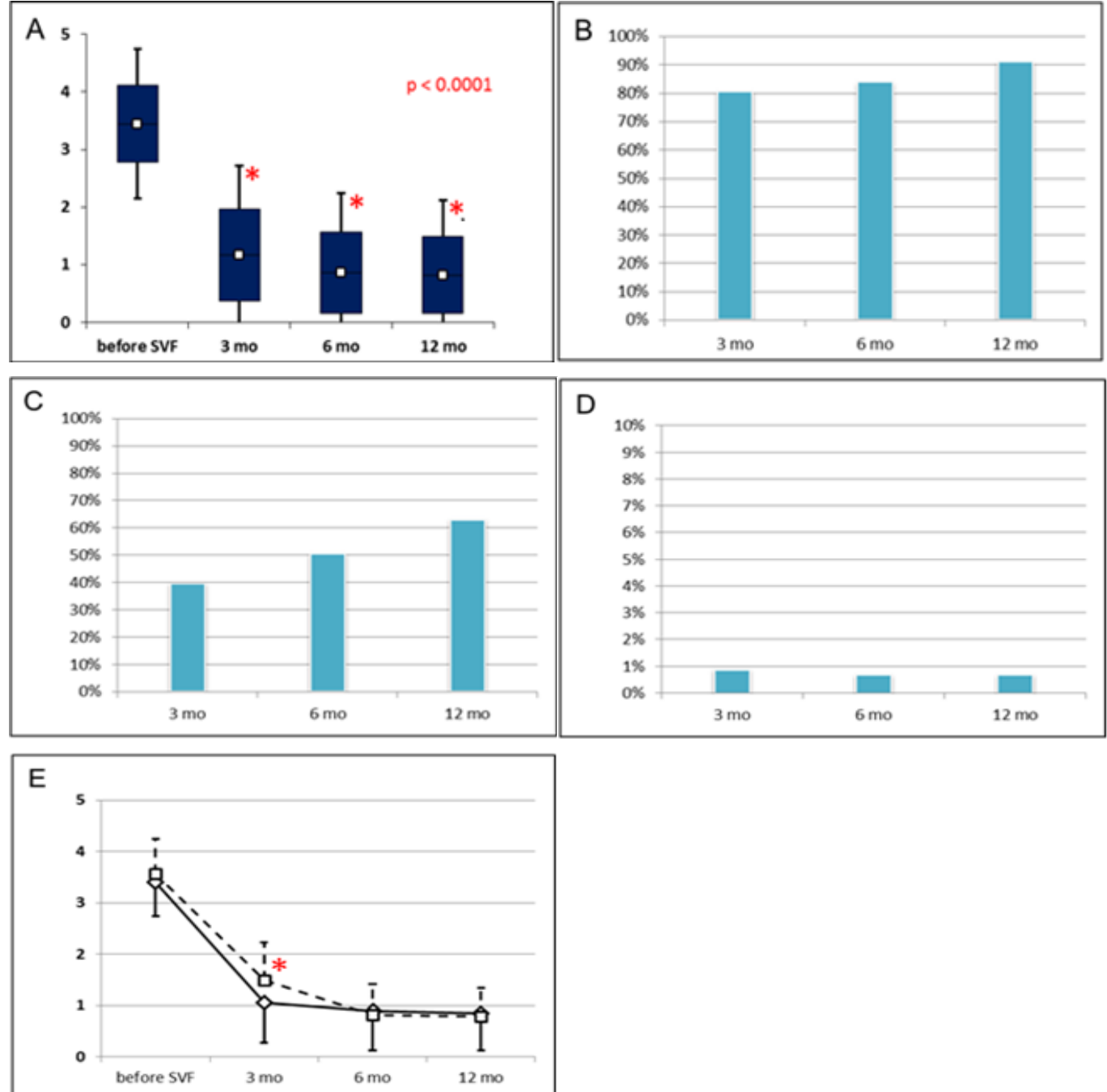

Figure 2. Evaluation of clinical outcome based on Modified KOOS/HOOS Score.

A calculation of the Score is based on 5 parameters: pain, number of painkillers per week, limping at walk, extent of joint movement and stiffness. (A): Significant improvement in Score ${ }^{*}$ ) was observed 3, 6 and 12 months after SVF cell therapy compared to the status before SVF cell therapy ( $\left.<0.0001\right)$. Means \pm SD [blue box], and \pm 1.96 SD [black bars] are shown. (B): Percentage of patients with at least 50\% Score improvement. (C): Percentage of patients with at least $75 \%$ Score improvement. (D): Comparison of Scores in patients treated with SVF cells isolated with Kit I or Kit II. Significant difference was noticed between Kits at 3 months after SVF cell therapy (*). Means - SD are shown for Kit I [full line] and means + SD are shown for Kit II [interrupted line]. (E): Comparison of Scores between the group of men and women. Significant difference was noticed between men and women before SVF therapy and at 3 months after the therapy $\left(^{*}\right)$, but not at 6 and 12 months after the procedure. Means - SD are shown for men [full line] and means + SD are shown for women [interrupted line]. (F): Comparison of Scores in patients younger than median age ( $<62$ years) and older than median age $(\geq 62$ years). Significant difference was noticed between younger and older patients before SVF therapy and at 3,6 and 12 months after the therapy $(*)$. Means - SD are shown for patients younger than 62 years [full line] and means + SD are shown for patients 62 years old and older [interrupted line].

SVF cell therapy case control study, 1856 joints were treated in 1128 patients and we were able to demonstrate safety with no serious side effects reported in 1-4.5 years of follow-up and clinical improvement in a vast majority of patients. Some patients experienced local pain and swelling at the injection site, but those symptoms were lasting shortly and were well controlled with common analgesics. Not surprisingly, most patients were treated for knee and/or hip OA and our treatment strategy allowed multiple joint treatments during one surgical procedure. Based on previous studies demonstrating migratory capability of MSCs [8-12] we allowed intraarticular or periarticular (synovial stroma or loose connective tissue immediately adjacent to the joint cartilage) application of SVF cells. We hypothesized that stem cells as well as other regenerative stromal cells may contribute to the cartilage healing process via two mechanisms: 1) paracrine effect and 2) cell migration, differentiation and proliferation. Our clinical observations are in agreement with this hypothesis and with the animal study [9], which brought direct evidence for such mechanism of cartilage regeneration using cell labeling techniques that clearly demonstrated long-term persistence of transplanted stem cells in the cartilage and adjacent synovial and other loose connective tissue. We did not observe any difference in clinical response after intraarticular or periarticular application of SVF cells. This is probably due to capacity of these cells to migrate to the site of injury where they are able to execute the healing effect.

At this point, we should also clarify the terminology regarding the source of SVF cells. In the vast majority of scientific publications only the term adipose tissue is used, but the true source of SVF cells is not the adipose part but only the stromal (ie. loose connective tissue) part of the fat obtained typically by liposuction. Histologically, the fat lobules 
Michalek J (2017) Stromal vascular fraction cells of adipose and connective tissue in patients with osteoarthritis: A case control prospective multi-centric nonrandomized study
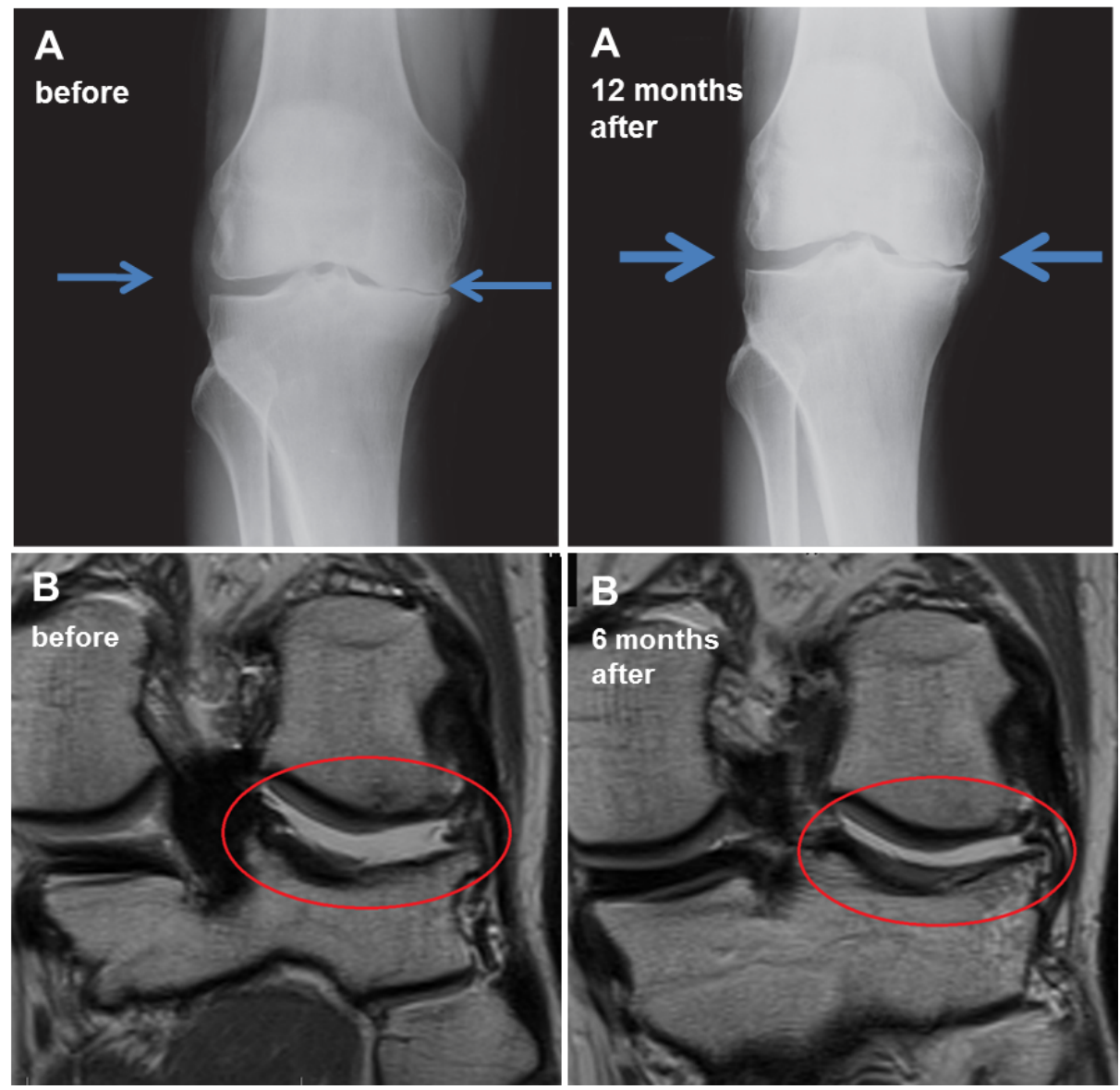

Figure 3. X-ray and magnetic resonance imaging (MRI) results of the joints before and after SVF cell therapy.

(A): X-ray results of 56 year old man with right knee grade 3 osteoarthritis and kissing bone phenomena in a medial compartment. X-ray 12 months after SVF cell therapy shows widening of the joint space [arrows], most likely due to greater cartilage volume. X-ray was performed by direct radiography system Sedecal CXDI 55G (Spain) with read-out detector Canon CXDI (Japan). (B): MRI results (proton density-weighted images in coronal plane) of 45 year old man with grade 2 osteoarthritis with chondral defects, loose chondral flap and irregularities of subchondral cortical bone of lateral compartment of the left knee joint [encircled in red]. MRI performed at 6 months after SVF cell therapy at the same level shows reintegration of the flap, reconstitution of chondral defects with a thin layer of chondral overgrowth and improved outlining of the subchondral cortex. MRI was performed by $1.5 \mathrm{~T}$ MRI Toshiba Excelart Vantage XGV Atlas (Japan). (C): MRI results (proton density-weighted images in coronal plane) of 49 year old man with grade 3 osteoarthritis and subchondral bone lesion with control at the same level 18 months after SVF cell therapy. The cartilage defect leading to the defect of subchondral cortical bone disappeared on the control MR image and is covered by regenerated smooth chondral layer. MRI was performed by 1.5 T MRI Toshiba Excelart Vantage XGV Atlas (Japan).

are surrounded by a loose connective tissue and the SVF cells reside in the loose connective tissue that also home capillaries and small vessels. Stroma is a broadly used term for the loose connective tissue that contains mesenchymal stem cells and other cells like fibroblasts, macrophages, adipocytes, mast cells and leukocytes. Synovia of articulated joints is also intimately associated with the loose connective tissue which is homologous to the loose connective tissue of the adipose tissue [29]. Thus, in our clinical study we were aiming to enrich the population of stem and other regenerative cells in a close proximity to damaged cartilage. In a human study we are limited in direct cell imaging in comparison to animal studies [9]. On the other hand, we can demonstrate indirectly the healing potential of SVF cell therapy in OA using clinical examinations and symptom scoring as well as objective visualization of damaged joints by MRI and X-ray imaging.

Despite several techniques for SVF cells isolation exist [12,15,21], maximal cell yields are obtained after collagenase digestion of adipose tissue [12]. Here we demonstrate that collagenase digestion may lead to better short term results in a clinical outcome at 3 months, but it is not clear if such short-term effect can be caused by the autologous plasma or larger cell number contained in that cell suspension. On the other hand, later on at 6 and 12 months after SVF cell administration, we did not observe any significant difference between usage of SVF cells that were processed with or without enzymatic digestion of the adipose tissue. In addition, there are similar results with comparable numbers of viable SVF cells that can be obtained without collagenase digestion when larger amounts of adipose tissue are processed. Almost $90 \%$ of patients were diagnosed with grade $2-3 \mathrm{OA}$ and almost $85 \%$ patients were overweight or obese. We were able to demonstrate that cartilage regeneration is slower during the first 3 to 6 months in patients with higher BMI and in patients with higher OA grade. But later on, at 6 and 12 months after SVF cell therapy, there is no difference in clinical outcome based on BMI and OA grade status. In obese people, the mechanical pressure on cartilage of the weight-bearing joints is extremely high leading to more degenerative changes of the weightbearing joints. We are demonstrating that despite there are still differences in a short term response (evaluated at 3 months after cell therapy), there is no significant difference in a clinical response after 6 or 12 months. The regenerative potential of SVF cells probably takes longer in obese patients to regenerate the cartilage.

Not surprisingly, higher age is associated with higher Score before and stays higher throughout the follow-up after cell therapy 

randomized study

in comparison to younger patients. Yet, dramatic Score decrease was significant after SVF cell therapy at any age. Even patients in their seventies, eighties or even nineties, who are typically not qualified for TJA because of their age and a general health status, can undergo SVF cell therapy without any serious side effects. Also, most patients benefited from SVF cell therapy despite the fact that more than $45 \%$ of them were TJA candidates. During the median follow-up 17.2 months there were only 4 patients who required TJA. All of them underwent hip joint replacement and all of them had grade $4 \mathrm{OA}$ of that hip joint. None of patients with other than hip OA required TJA. We cannot draw strong conclusions out of this finding, but we can suggest to undergo the SVF cell therapy in earlier stages, especially in case of hip OA, when clinical symptoms of OA are present and leading to decreased quality of life. In addition, our data clearly demonstrate a durable effect of single injection of adipose-derived SVF cells. Similar finding was documented previously with bone marrow-derived cultured MSCs therapy in patients with osteoarthritis [11]. In this study, there were $67.8 \%$ of patients with knee OA candidates for total knee arthroplasty and $6.9 \%$ reported that they opted for knee replacement in a median follow-up of 435 days [11].

Other treatment options are used in a clinical practice to alleviate symptoms such as pain and stiffness in OA patients, although none of them led to regeneration of joint connective tissue including cartilage: administration of analgesic, non-steroidal anti-inflammatory drugs and/or corticosteroids. However, these medications may have broad spectrum of adverse effects, namely in gastrointestinal tract, heart, liver, kidneys, and other organs, especially during long-term use [30]. In case of advanced stage large-joint $\mathrm{OA}$, standard treatment consists in surgical removal of the affected joint and its replacement with an artificial joint. Total joint arthroplasty represents rather extensive surgery which is associated with considerable risk of serious side effects and post-operative complications including myocardial infarction, stroke, systemic infection or increased risk of death after TJA [2-5].

Typically, patients in our case control study were administered large amounts of painkillers, ie. mainly analgesics or non-steroidal anti-inflammatory drugs, before the SVF administration. In order to compare the amount of painkillers taken before and after the SVF cell application, the quantity of these drugs in a form of pills or topical analgesic creams used by patients was assessed, evaluated and used as one of the parameters in calculation of the Modified KOOS/ HOOS Clinical Score to evaluate clinical effect of the therapy. We have observed that the quantity of painkillers (data not shown), as well as the Score (Figure 2A) were significantly decreased after the SVF therapy. Despite the limitation of our study that did not contain the control group of patients with $\mathrm{OA}$, we can assume that, due to a long term use (at least 6 months, but typically several years) of painkillers prior to SVF administration, those patients would continue in painkillers consumption at the same or even larger amounts of painkillers as the diseases progresses, without SVF cell application. Altogether, given that the amount of painkillers used was significantly decreased in patients after the SVF cell administration, we can assume that this therapeutic strategy is both safe and effective in most of the patients treated.

In addition, there are also other treatment approaches to OA, such as intraarticular administration of platelet rich plasma or hyaluronic acid, sometimes called viscosupplementation. Although these methods are also available for patients with symptomatic OA, they typically involve a series of intraarticular injections with increased potential risks associated with repeated joint injections. In contrast, the results of our case control study are based on a single, intra- or periarticular administration of SVF cells with documented safety and a relatively long term clinical effect with a median follow-up time 17.2 months (range 12.1-54.3 months). Therefore, it would be difficult to compare the effect of a single dose of autologous SVF cells with a series of platelet rich plasma or hyaluronic acid injections.

Despite safety and efficacy of SVF cell therapy, there are some limitations in our case control study. There is no guarantee that such cell therapy can lead to a definite cure of degenerative OA. The patients are further monitored and longer follow-up data will help to answer question about durability and long-term safety of SVF cell therapy. Another limitation of our study is no randomization and no placebo control. There were two reasons for designing that case control study: 1) ethical aspect and 2) economical aspect. We believe it would be rather unethical to ask placebo group of patients to undergo liposuction and placebo administration to the joint with OA. Since this study was designed as autologous cell therapy, there is strong previously documented clinical evidence of safety of autologous non-manipulated or minimally manipulated cell therapies [31]. In the first decade of the 21st century, more than 17,000 scientific articles involving 2,724 cell therapy clinical trials were published [32]. These results include 323,000 patients treated with more than 675,000 cell therapy units. The treatments were very safe and often very effective in the treatment of various diseases with the potential to significantly improve health worldwide $[10,31,32]$. Second economical aspect of our study preparation was based on estimation of extreme costs associated with a new drug development. The costs of phase I to phase III clinical trials leading to the new drug registration are estimated to be 300 million to 1 billion USD. Furthermore, once such budget is raised, new drug is tested in a double-blind, randomized, placebo-controlled clinical trial and finally registered based on safety and efficacy profile. The health care providers worldwide are exposed to extreme costs associated with eligible patient treatments after such registration. On the other hand, a case control study, if well designed and if strong evidence for minimal risks based on previous studies exists, can lead to a cost-effective, safe, ethical and objective evaluation of a novel treatment. One of such examples can be a case control study using autologous non-manipulated or minimally manipulated cells.

\section{Conclusion}

Autologous stromal vascular fraction cell therapy of degenerative osteoarthritis is safe and clinically effective strategy leading to improved quality of life. This conclusion is based on the present case control study of 1128 adult patients.

\section{Financial support} Republic

This work was supported in part by Cellthera, s.r.o., the Czech

\section{Disclosure of potential conflicts of interest}

JM is CEO of Cellthera, s.r.o., other authors do not declare any conflicts of interest.

\section{Author contributions}

JM was responsible for conception and design, financial support, data analysis and interpretation, manuscript writing and final approval of manuscript; RM, LL, KP, MP, JR, MC, AC, AD were responsible for provision of study patients and materials, collection and assembly of data; JM sr. was responsible for data analysis and interpretation; MC, $\mathrm{ZK}, \mathrm{PJ}$ and $\mathrm{ZD}$ were responsible for collection and assembly of data and 
Michalek J (2017) Stromal vascular fraction cells of adipose and connective tissue in patients with osteoarthritis: A case control prospective multi-centric nonrandomized study

administrative support; JK and JT were responsible for radiology data collection and assembly; KP and ZD participate in manuscript writing and final approval of manuscript.

\section{Acknowledgement}

Thisworkwassupported in partbygrantsNo.CZ.1.07/2.3.00/20.0012 and LM2011017 of the Ministry of Education, Youth and Sports of the Czech Republic and European Union Operational Program Education for Competitiveness.

\section{References}

1. Helmick CG, Felson DT, Lawrence RC, Gabriel S, Hirsch R, et al. (2008) Estimates of the prevalence of arthritis and other rheumatic conditions in the United States. Part II. Arthritis Rheum 58: 26-35. [Crossref]

2. Lassen MR, Ageno W, Borris LC, Lieberman JR, Rosencher N, et al. (2008) Rivaroxaban versus enoxaparin for thromboprophylaxis after total knee arthroplasty. N Engl J Med 358: 2776-2786. [Crossref]

3. Parry MC, Smith AJ, Blom AW (2011) Early death following primary total knee arthroplasty. J Bone Joint Surg Am 93: 948-953. [Crossref]

4. Schrama JC, Espehaug B, Hallan G, Engesaeter LB, Furnes O, et al. (2010) Risk of revision for infection in primary total hip and knee arthroplasty in patients with rheumatoid arthritis compared with osteoarthritis: a prospective, population-based study on 108,786 hip and knee joint arthroplasties from the Norwegian Arthroplasty Register. Arthritis Care Res (Hoboken) 62: 473-479. [Crossref]

5. Thorey F, Reck F, Windhagen H, von Lewinski G (2008) Influence of bone density on total hip resurfacing arthroplasty in patients with osteonecrosis of the femoral head - a radiological analysis. Technol Health Care 16: 151-158. [Crossref]

6. Hematti P, Keating A. Mesenchymal stromal cells in regenerative medicine: A Perspective. In: Hematti P, Keating A (2013) Mesenchymal Stromal Cells. Biology and clinical applications. New York: Humana Press Pp. 3-16.

7. Black LL, Gaynor J, Gahring D, Adams C, Aron D, et al. (2007) Effect of adiposederived mesenchymal stem and regenerative cells on lameness in dogs with chronic osteoarthritis of the coxofemoral joints: a randomized, double-blinded, multicenter, controlled trial. Vet Ther 8: 272-284. [Crossref]

8. Koga H, Shimaya M, Muneta T, Nimura A, Morito T, et al. (2008) Local adherent technique for transplanting mesenchymal stem cells as a potential treatment of cartilage defect. Arthritis Res Ther 10: R84. [Crossref]

9. Sato M, Uchida K, Nakajima H, Miyazaki T, Guerrero AR, et al. (2012) Direct transplantation of mesenchymal stem cells into the knee joints of Hartley strain guinea pigs with spontaneous osteoarthritis. Arthritis Res Ther 14: R31. [Crossref]

10. Strioga M, Viswanathan S, Darinskas A, Slaby O, Michalek J (2012) Same or not the same? Comparison of adipose tissue-derived versus bone marrow-derived mesenchymal stem and stromal cells. Stem Cells Dev 21: 2724-2752. [Crossref]

11. Centeno CJ, Schultz JR, Cheever M, Freeman M, Faulkner S, et al. (2011) Safety and complications reporting update on the re-implantation of culture-expanded mesenchymal stem cells using autologous platelet lysate technique. Curr Stem Cell Res Ther 6: 368-378. [Crossref]

12. Mizuno H, Tobita M, Uysal AC (2012) Concise review: Adipose-derived stem cells as a novel tool for future regenerative medicine. Stem Cells 30: 804-810. [Crossref]

13. Yoshimura K, Suga H, Eto H (2009) Adipose-derived stem/progenitor cells: roles in adipose tissue remodeling and potential use for soft tissue augmentation. Regen Med 4: 265-273. [Crossref]
14. Bui KH, Duong TD, Nguyen TN, Nguyen TD, Le VT, et al. (2014) Symptomatic knee osteoarthritis treatment using autologous adipose derived stem cells and platelet-rich plasma: a clinical study. Biomed Res Ther 1: 2-8.

15. Gimble JM, Guilak F, Bunnell BA (2010) Clinical and preclinical translation of cell/ based therapies using adipose tissue/derived cells. Stem Cell Res Ther 1: 19.

16. Koh YG, Choi YJ, Kwon SK, Kim YS, Yeo JE (2015) Clinical results and secondlook arthroscopic findings after treatment with adipose-derived stem cells for knee osteoarthritis. Knee Surg Sports Traumatol Arthrosc 23: 1308-1316. [Crossref]

17. Vangsness CT, Farr J, Boyd J, Dellaero DT, Mills CR, et al. (2014) Adult human mesenchymal stem cells delivered via intra-articular injection to the knee following partial medial meniscectomy: a randomized, double-blind, controlled study. $J$ Bone Joint Surg Am 96: 90-98. [Crossref]

18. Bernardo ME, Locatelli F, Fibbe WE (2009) Mesenchymal stromal cells: a nove treatment modality for tissue repair. Ann N Y Acad Sci 1176: 101-117. [Crossref]

19. Guilak F, Awad HA, Fermor B, Leddy HA, Gimble JM (2004) Adipose-derived adult stem cells for cartilage tissue engineering. Biorheology 41: 389-399. [Crossref]

20. Murphy JM, Fink DJ, Hunziker EB, Barry FP (2003) Stem cell therapy in a caprine model of osteoarthritis. Arthritis Rheum 48: 3464-3474. [Crossref]

21. Gimble JM, Bunnell BA, Chiu ES, Guilak F (2011) Concise review: Adipose-derived stromal vascular fraction cells and stem cells: Let's not get lost in translation. Stem Cells 29: 749-754. [Crossref]

22. Illouz YG, Sterodimas A (2009) Autologous fat transplantation to the breast: a personal technique with 25 years of experience. Aesthetic Plast Surg 33: 706-715. [Crossref]

23. Evans CH, Kraus VB, Setton LA (2014) Progress in intra-articular therapy. Nat Rev Rheumatol 10: 11-22. [Crossref]

24. Koh YG, Choi YJ (2012) Infrapatellar fat pad-derived mesenchymal stem cell therapy for knee osteoarthritis. Knee 19: 902-907. [Crossref]

25. Pak J (2011) Regeneration of human bones in hip osteonecrosis and human cartilage in knee osteoarthritis with autologous adipose-tissue-derived stem cells: a case series. $J$ Med Case Rep 5: 296. [Crossref]

26. Aust L, Devlin B, Foster SJ, Halvorsen YDC, Hicok K, et al. (2004) Yield of human adipose-derived adult stem cells from liposuction aspirates. Cytotherapy 6: 7-14. [Crossref]

27. Caplan AI (2009) Why are MSCs therapeutic? New data: new insight. J Pathol 217 318-324. [Crossref]

28. Varma MJ, Breuls RG, Schouten TE, Jurgens JF, Bontkes HJ, et al. (2007) Phenotypical and functional characterization of freshly isolated adipose tissue-derived stem cells. Stem Cells Dev 16: 91-104. [Crossref]

29. Ross MH, Pawlina W (2011) Histology: a Text and Atlas. 6-th ed. Wolters Kluver Lippincott Williams \& Wilkins. Pp. 98-104.

30. O’Neil CK, Hanlon JT, Marcum ZA (2012) Adverse effects of analgesics commonly used by older adults with osteoarthritis: focus on non-opioid and opioid analgesics. $\mathrm{Am}$ J Geriatr Pharmacother 10: 331-342. [Crossref]

31. Mason C, Manzotti E (2010) Regenerative medicine cell therapies: numbers of units manufactured and patients treated between 1988 and 2010. Regen Med 5: 307-313. [Crossref]

32. Culme-Seymour EJ, Davie NL, Brindley DA, Edwards-Parton S, Mason C (2012) A decade of cell therapy clinical trials (2000-2010). Regen Med 7: 455-462. [Crossref]

Copyright: $\odot 2017$ Michalek J. This is an open-access article distributed under the terms of the Creative Commons Attribution License, which permits unrestricted use, distribution, and reproduction in any medium, provided the original author and source are credited. 